\title{
Impact of Informal Caregivers Training Program On Geriatric Patients' Functional Status and Post-Stroke Depression
}

\author{
Amany M. Shebl ${ }^{1}$, Soad H. Abd Elhameed ${ }^{2}$ \\ ${ }^{1}$ Medical-Surgical Nursing Department, Faculty of Nursing, Mansoura University, Egypt \\ ${ }^{2}$ Gerontological Nursing Department, Faculty of Nursing, Mansoura University, Egypt
}

\begin{abstract}
Background: Stroke is a suddenly occurring condition in which the blood supply to a part of the brain is interrupted. It could soon be the most common cause of death worldwide. Older adults are more affected by stroke and the majority of stroke survivors have a disability. Training caregivers in skills essential for the day to day management of disabled elder with stroke is likely to have a role in reducing the burden of care and contribute to improved patients outcomes.
\end{abstract}

Aim: determine the impact of informal caregivers training program on geriatric patients' functional status and post-stroke depression.

Method: quasi-experimental research design was used. The study was carried out on 45 elderly patients and their informal caregivers in the inpatient neurological departments and neurological outpatient clinics of ElMansoura University Hospital. Data was collected using 5 tools and the collected data was analyzed using descriptive statistics and analytical statistics.

Conclusion: the present study revealed that caregivers training affect positively the geriatric patients' functional status and post-stroke depression. An improvement in the geriatric patients' functional status and post-stroke depression after implementation of the training program was observed and also the caregivers' knowledge and practices level was improved.

Keywords: Informal caregiver, Geriatric Patients, Functional status, Post-stroke depression, Stroke.

\section{Introduction}

Stroke is an interruption of blood circulation to the brain causing a neurologic deficit reflecting the area of the brain affected ${ }^{1}$. Older adults are more affected by stroke than other age categories. Moreover, stroke is considered the third leading cause of long-term disability and considered the number two cause of death worldwide ${ }^{2,3}$. According to the World Health Organization $2009^{4}, 15$ million people suffer from stroke worldwide each year. Of these, 5 million die and another 5 million are permanently disabled. Available data from Arab countries indicates that the unadjusted incidence of stroke is lower than in more developed countries but higher than the sub-Saharan Africa ${ }^{5}$. In 2007, epidemiological studies reported the incidence of stroke in Egypt to be 8/ 1000 and it is more prevalent among males (58.2\%) ${ }^{6}$. Review of Mansoura Main University Hospital; statistical records revealed that about 770 elderly patients were admitted to the neurology departments during the year 2010, of them $590(76.6 \%)$ had stroke ${ }^{7}$.

Persons with stroke often experience physical, cognitive, and emotional problems that limit the performance of activities of daily living (ADL's), restrict participation in significant societal roles, and prevent successful re-entry into community. These changes in function following stroke require rehabilitation, and /or continued care ${ }^{8}$. Previous researches demonstrates recovery of functional status post stroke is associated with a number of factors, including age, gender, stroke type and severity, social support and education ${ }^{9,10}$. Post-stroke depression (PSD) in elderly patients has been considered the most common neuropsychiatric consequence of stroke up to 6-24 months after stroke onset and has been associated with poorer functional outcomes and reduced survival ${ }^{11,12}$. Accordingly, $70 \%$ of the stroke survivors receiving home health care services are older than 65 years old, and $60-70 \%$ of them have multi-diseases and over five to six medications daily with the responsibility of continuing care and recovery shifting to informal caregivers, often family members with little or no preparation or training ${ }^{13}$. Shorter hospital stays mean caregivers will play an increasingly important role in the care and continued rehabilitation of patients after stroke. The caregivers identify the information and training skills required to implement physical care as the most important of pre-discharge needs ${ }^{14}$.

Care giving is a very important task that post-stroke disabled patients understand very little and the informal caregivers make an important contribution to supply disabled stroke survivors at home ${ }^{15,16}$. Previous researches demonstrate that stroke survivors and their caregivers often lack the information necessary to help manage the recovery process at home ${ }^{17,18}$. Moreover, informal caregivers face the dual challenge of coming to terms with the sudden onset and subsequent disabling impact of stroke and the realization that the person may require long-term support ${ }^{19}$. Training caregivers in skills essential for the day to day management of disabled elder with stroke is likely to have a role in reducing the burden of care and contribute to improved patients 
outcomes. Caregiver training has additional advantages of reducing the costs of stroke care and improving patients' quality of life. Those with training tend to have less anxiety and stress and this help elders to engage in social relationships, to be optimistic about their future, to cope successfully with stressful situations and to feel in control of their lives. Also caregiving make people confident about their own abilities and a higher proportion of disabled stroke survivors achieved independence at an earlier stage ${ }^{15,20}$. Furthermore, the needs of patients and their caregivers require ongoing nursing assessment and adaptation of interventions in response to changing needs to optimize quality of life for both the patient and family caregiver ${ }^{21}$.

Aim of the study: this study was conducted in order to determine the impact of informal caregivers training program on geriatric patients' functional status and post-stroke depression.

\section{Materials And Method}

Materials

Research Design: Quasi-experimental research design was used in this study.

Settings: The study was carried out at the inpatient neurological departments (A\&B) and the neurological outpatient clinic of El-Mansoura University Hospital.

Subjects: The study Subjects included both patients and their caregivers selected from the neurological departments (A\&B) of Mansoura University Hospital.

A) Patients: All geriatric patients admitted to neurological departments (A\&B) of Mansoura University Hospital during a period of 3 months and fulfilling the following criteria: aged 60 years and above, diagnosed with stroke, able to communicate and accept to participate in the study. Their number amounted to 45 patients.

B) Caregivers: The number of informal caregivers included in the study was 45 persons and fulfilled the following criteria: responsible for providing care to the geriatric patient included in the study, don't have any physical disability and accept to participate in the study.

Tools of the study:-

Five tools were used to collect the data of this study.

Tool I: - Socio-demographic \& clinical data of the geriatric patients and their caregivers: structured interview schedule. This tool was developed by the researcher. The tool consisted of two parts:

Part I: Data about geriatric patients with stroke. It included items related to socio-demographic data as age, sex, marital status, occupation, level of education, income and its source. Health history of the elderly as date of hospital admission, previous hospitalization, number of previous hospitalization, causes of previous hospitalization, type of associated disease and type of medication taken. History of cerebral stroke as type of stroke, duration of disease, onset of disease, affected side, number of recurrence, type of treatment \& medication taken.

Part II: Data about caregivers of geriatric patients with stroke. It included items related to socio-demographic data of the caregivers as age, sex, marital status, occupation, level of education, relation with the elderly and medical history of the caregivers.

\section{Tool II: - Functional Independence Measure (FIM Instrument)}

The functional independence measure tool was developed by the American Academy of Physical Medicine and Rehabilitation and the American Congress of Rehabilitation Medicine and published by Hamilton et al. $(1987)^{22,23}$. This tool is used to assess the functional status of the older adults with stroke $e^{24}$. It includes 18 items covering six domains: self-care, sphincter control, transfers, locomotion, communication, and social cognition. All 18 items are scored into one of seven levels of function, ranging from complete dependence (level 1) to complete independence (level 7). The total FIM ratings have a potential range of 18 to 126 . The higher score indicating a greater level of functional independence.

\section{Tool III: - Patient Health Questionnaire (PHQ-9)}

The patient health questionnaire was developed by Spitzer et al. (1999) ${ }^{25}$. It is used for assessing and monitoring depression severity in geriatric patients. This tool is a short one questionnaire and suitable for geriatric patients with stroke ${ }^{26}$. In this study the researcher used a face to face interview tool to collect data as the majority of subjects are illiterate. The PHQ consists of 9 questions, each of which score zero (0) means not at all, a score of one (1) means Several days, a score of two (2) means more than half the days and a score of three (3) means nearly every day. The overall score of PHQ is ranged from 0 to 27 severity score. The lower total score indicating a good emotional status (Decreased level of depression). 


\section{Tool IV: - Caregivers' knowledge about care of geriatric patients with stroke structured interview} schedule

This tool was developed by the researcher based on relevant literature review ${ }^{13,16,27}$ to assess knowledge of caregivers related to care of elder patients with stroke. It include 17 questions on Arabic language related to; definition, causes of stroke, risk factors, signs and symptoms, complications, preventions, treatment, available community health services for stroke patients and importance of follow-up. The answers were scored based on the level of knowledge of the studied subjects. Each question had 3 possible responses: correct answers (2), incomplete answers (1), and incorrect answer (0). The total score is 34 . The higher score indicate a greater level of knowledge.

\section{Tool V: - Caregivers practices of geriatric patients with stroke care checklist}

This tool was developed by the researcher based on relevant literature review ${ }^{13,16,27}$ to assess the level of care practices of caregivers caring for elderly patients with stroke. It include 45 items related to; Proper use of assistive devices, Skills in moving the elder, Skin care, bladder care, bowel care and Communication skills. Scoring of the items on the checklist was made using a 3-point likert scale, a zero (0) scored for the items which not done, one (1) means done incorrectly and two (2) means done correctly. The total score is computed out of 90. The higher score indicates a greater level of geriatric patients caregivers practices.

\section{Method}

1. An official letter was issued to the manager of El-Mansoura University hospitals and director of the neurological departments to obtain his approval in order to collect the necessary data.

2. Study tools I (Socio-demographic \& clinical data of the geriatric patients and their caregivers: structured interview schedule), tool IV (Caregivers' knowledge about care of geriatric patients with stroke structured interview schedule) and tool V (Caregivers practices of geriatric patients with stroke care checklist) were developed by the researcher after reviewing the relevant literature.

3. Study tools II (FIM Instrument) and tool III (PHQ-9) were translated into Arabic.

4. Study tools I, II, III, IV and V were tested for content validity by a jury of 5 experts from related specialties. The necessary modifications were done accordingly. The reliability was assured by Spearman's correlation coefficient $r=0.952$ for tool II and $r=0.861$ for tool III.

5. Verbal consent was obtained from the study subjects after explanation of the purpose of the study.

6. Privacy of the subjects and confidentiality of the collected data was assured throughout the study. Study subjects were informed about their rights to withdrawn from the study at any time.

7. A pilot study was carried out on 10 of elderly patients with stroke and their principle caregivers at the neurological department of El-Mansoura University Hospital before starting the data collection to test the feasibility of the tools and to make the necessary modifications. These patients were not included in the study.

8. Each elderly was interviewed individually by the researcher to collect the necessary data using part I in tool I (Socio-demographic \& clinical data of the geriatric patients and their caregivers: structured interview schedule) pre program sessions implementation and tool II (FIM Instrument) \& tool III (PHQ-9) pre and post implementation of the training program sessions.

9. Assessment of every informal caregiver was carried out by the researcher in neurological department using part II in tool I (Socio-demographic \& clinical data of the geriatric patients and their caregivers: structured interview schedule), tool IV (Caregivers' knowledge about care of geriatric patients with stroke structured interview schedule), tool V (Caregivers practices of geriatric patients with stroke care checklist) pre and post the implementation of the training program sessions.

10. Based on the assessment find and literature review the researcher plan for the training sessions and implementation of the program. A booklet containing the content of the program was designed by the researcher. It was written in a simple Arabic language and supplemented with photos and illustrations to help the patients and caregivers understanding the content.

11. The researcher started the data collection and implementation of the program from the first of April 2012 and the evaluation ended on January 2013. Data collection schedule days start from 10 am to $2 \mathrm{pm}$.

\section{The caregiver training program:-}

The sessions were implemented in the neurological departments for all assigned caregivers. The training was carried out by dived caregivers into groups according to their needs based on assessment of their knowledge and practices about stroke and care provided. Each group ranged from 3-4 caregivers. The training was provided for 3 sessions, on 13 aspects of stroke care, each session took 30-45 minutes for 5 days per week. 
The sessions were carried as follows:-

First session: At the beginning of this session, the researcher introduced herself, explained the aim of the training sessions, and methods of teaching to be used. The informal caregivers were then introduced to the basic knowledge about stroke. It included information about: definition of stroke, causes and risk factors, signs and symptoms, complications of stroke, measures needed to prevent subsequent stroke, health education about nutrition and health education about medications.

Second Session: During this session, the researcher made demonstration about skills of moving the elder and use of assistive devices. It included information about: how to move the elder patients, safety measures to prevent falls and common assistive devices used for elders with stroke.

Third session: During this session, the researcher gave information about preventive measures of pressure ulcer, fecal impaction and urinary tract infection (Skin care, Bowel and bladder care), communication skills and available community health services for elders with stroke in Mansoura.

During the training sessions the researcher used simple, brief and clear words during each session. At the end of each session, a brief summary was given by the researcher, emphasizing the most important points. Before the start of each session, caregivers were asked questions related to the topics discussed in the previous session to identify their learning achievement.

Methods of teaching used in the training sessions: Lectures, Discussions, Booklet and Demonstration.

Media used: Pictures, assistive devices, videos and colored booklet.

\section{Evaluation of the training program:-}

Immediately after the implementation of the training program each caregiver was assessed using the study tool IV (Caregivers' knowledge about care of geriatric patients with stroke structured interview schedule) and tool V (Caregivers practices of geriatric patients with stroke care checklist) to determine the effect of the sessions on their knowledge and practices after the training sessions.

The evaluation of the elderly included in the study was carried out after 1,3and 6 months post program implementation in the neurological outpatients' clinic when patients come for the follow up. The patients were evaluated using the study tool II (FIM Instrument) and tool III (PHQ-9) to determine the effect of the caregivers training program on the geriatric patients post stroke depression and their functional status.

\section{Statistical analysis:}

Data were analyzed using the Statistical Package of Social Science (SPSS) software version 16.0. The 0.05 level was used as the cut off value for statistical significance and the following statistical measures were used: descriptive statistics (count \& percentage, arithmetic mean \&standard deviation) and analytical statistics (t-test \& spearman's correlation coefficient).

\section{Results}

Table 1 shows the socio-demographic characteristics of the geriatric patients with cerebral stroke. The mean age of them was $66 \pm 8.5$ years. Females were more prevalent; they constituted $57.8 \%$ of the elderly. More than half of the studied elderly were widowed. Illiteracy was prevailing among $82.2 \%$ of the studied elderly. Also, it was observed that more than half (53.3\%) of the studied elders were housewives and that the mean monthly income was $237.5 \pm 121.29 \mathrm{LE} /$ month.

Table (1): Distribution of the geriatric patients with cerebral stroke according to their socio-demographic characteristics

\begin{tabular}{|l|c|c|}
\hline \multicolumn{1}{|c|}{ Sociodemographic Characteristics } & Frequency (n=45) & Percent (\%) \\
\hline Age (in years): & 29 & 64.4 \\
Young- old (60- ) & 13 & 28.9 \\
Middle-old (75-) & 3 & 6.7 \\
Old-old (85+) & \multicolumn{2}{|c|}{} \\
\hline \multicolumn{2}{|c|}{ Mean \pm SD $=66 \pm 8.5$} & 57.8 \\
\hline Sex : & 26 & 42.2 \\
Female & 19 & 48.9 \\
Male & 22 & 51.1 \\
\hline Marital status : & 23 & \\
Married & & \\
Widowed & & \\
\hline
\end{tabular}




\begin{tabular}{|l|c|c|}
\hline Level of education : & 37 & 82.2 \\
Illiterate & 7 & 15.6 \\
Read \& write & 1 & 2.2 \\
University education & & 53.3 \\
\hline Occupation before retirement : & 24 & 46.7 \\
House wife & 21 & 53.3 \\
Employee & & 24 \\
\hline Monthly income (L.E.): & 21 & 46.7 \\
Not enough & & \\
Enough & & \\
\hline \multicolumn{2}{|c|}{ Mean \pm SD $=237.5 \pm 121.29$} \\
\hline
\end{tabular}

Table 2 shows the distribution of the geriatric patients with cerebral stroke according to their medical history. It was observed from the table that, more than two third (71.1\%) of the studied sample reported no previous hospitalization. Hypertension was the most common disease among the elderly $(95.0 \%)$, followed by diabetes mellitus $(40.0 \%)$ and osteoarthritis (12.5\%). In relation to the current medications used, it was observed that all the studied elders $(100.0 \%)$ used anti-thrombotic, anti-coagulants drugs and anti-hypertensive drugs, followed by antacids (77.5\%) and hypoglycemic medication $(40.0 \%)$.

Table (2): Distribution of the geriatric patients with cerebral stroke according to their medical history

\begin{tabular}{|l|c|c|}
\hline \multicolumn{1}{|c|}{ Medical History } & Frequency (n=45) & Percent (\%) \\
\hline Previous hospitalization: & & \\
No & 32 & 71.1 \\
Once & 9 & 20.0 \\
Twice & 4 & 8.9 \\
\hline Associated disease \# & 38 & 95.0 \\
Hypertension & 16 & 40.0 \\
Diabetes mellitus & 5 & 12.5 \\
Osteoarthritis & 3 & 7.5 \\
Coronary artery disease & 3 & 7.5 \\
Liver diseases & & \\
Current medications used \#: & 40 & 100.0 \\
Anti-thrombotics & 40 & 100.0 \\
Anti-coagulants & 40 & 77.5 \\
Anti-hypertensives & 31 & 40.0 \\
Antacids & 16 & \\
Hypoglycemics & & \\
\hline
\end{tabular}

\# More than one answer was given.

Table 3 shows the distribution of the geriatric patients with cerebral stroke according to the present medical condition. It was observed that, all the studied elders suffered from ischemic stroke. The majority of the elderly $(91.1 \%)$ had stroke for less than 2 weeks, and only $(8.9 \%)$ suffered from stroke since 2-3 weeks. More than half (51.1\%) of the studied elderly had stroke in the right side and the rest (48.9\%) in the left side.

Table (3): Distribution of the geriatric patients with cerebral stroke according to the present medical condition

\begin{tabular}{|l|c|c|}
\hline \multicolumn{1}{|c|}{ Item } & Frequency (n=45) & Percent (\%) \\
\hline $\begin{array}{l}\text { Type of stroke: } \\
\text { Ischemic }\end{array}$ & 45 & 100.0 \\
\hline $\begin{array}{l}\text { Duration: } \\
<2 \text { weeks } \\
2-3 \text { weeks }\end{array}$ & 41 & 91.1 \\
\hline Onset : & 4 & 8.9 \\
Acute & & \\
Recurrent & 32 & 71.1 \\
\hline No. of recurrence: & 13 & 28.9 \\
Once & $(\mathrm{n}=13)$ & 84.6 \\
Twice & 11 & 15.4 \\
\hline Side: & 2 & \\
Right & & 51.1 \\
Left & 23 & 48.9 \\
\hline
\end{tabular}

Table 4 shows the socio-demographic characteristics of the studied caregivers. The mean age of the caregivers was $33.38 \pm 7.67$ and female subjects constituted more than half $(57.8 \%)$. More than three quarter $(77.8 \%)$ of 
the studied caregivers were married and about two third of the caregivers read and write. Moreover, it was observed that 48.9 . $\%$ of the caregivers was employee and $44.4 \%$ were house wives.

Table (4): Distribution of the geriatric patients' caregivers according to their socio-demographic characteristics

\begin{tabular}{|l|l|l|}
\hline \multicolumn{2}{|c|}{ Sociodemographic Characteristics } & \multicolumn{2}{c|}{ Percent (\%) } \\
\hline Age (in years): & & \\
$<30$ & 19 & 42.2 \\
$30-$ & 18 & 40.0 \\
$40+$ & 8 & 17.8 \\
\hline \multicolumn{1}{|c|}{ Mean \pm SD $=\mathbf{3 3 . 3 8} \pm \mathbf{7 . 6 7}$} & \\
\hline Sex : & & 57.8 \\
Female & 26 & 42.2 \\
Male & 19 & \\
\hline Marital status : & & 77.8 \\
Married & 35 & 20.0 \\
Single & 9 & 2.2 \\
Widow & 1 & \\
\hline Level of education : & & 13.3 \\
Illiterate & 6 & 64.5 \\
Read \& write & 29 & 22.2 \\
University education & 10 & \\
\hline Occupation : & & 48.9 \\
Employee & 22 & 44.4 \\
House wife & 20 & 6.7 \\
Skilled & 3 & 33.3 \\
\hline Relation with the elderly patients: & 15 & 35.6 \\
Sons & 16 & 31.1 \\
\hline Daughters & 14 & \\
Sons' wife & & \\
\hline
\end{tabular}

Table 5 shows the total knowledge and practice score of the caregivers' pre and post the implementation of the training program. It appears that, the mean total knowledge and practice score post the training was increased (improved) significantly. The difference was high statistically significant $(\mathrm{P}=0.000)$.

Table (5): Total knowledge and practice score of geriatric patients' caregivers pre-post the training program implementation

\begin{tabular}{|l|c|c|c|}
\hline \multirow{2}{*}{ Item } & Before session & After sessions & \multirow{2}{*}{ t-test } \\
\cline { 2 - 3 } & Mean \pm SD & Mean \pm SD & 18.206 \\
\hline Total knowledge score & $9.178 \pm 2.61$ & $22.2 \pm 4.08$ & $(0.000)^{*}$ \\
\hline Total practice score & & & 15.657 \\
& $20.62 \pm 5.73$ & $48.82 \pm 13.03$ & $(0.000)^{*}$ \\
\hline
\end{tabular}

*Significance at $\mathrm{p} \leq 0.05$

Table 6 describes the changes in the geriatric patients' functional status and post-stroke depression pre and post the training program implementation. It was observed that the functional and emotional status level increased (improved) significantly after implementation of the program at 1,3, and 6 months. The difference was statistically significant $(\mathrm{P}=0.000)$.

Table (6): Mean score of the functional status and post-stroke depression of the geriatric patients pre-post the training program implementation

\begin{tabular}{|c|c|c|c|c|}
\hline \multirow[t]{2}{*}{ Item } & Before sessions & After 1 month & After 3 months & After 6 months \\
\hline & Mean \pm SD & Mean \pm SD & Mean \pm SD & Mean \pm SD \\
\hline Functional status (FIM) & $52.29 \pm 15.95$ & $60.11 \pm 17.39$ & $75.04 \pm 17.85$ & $76.58 \pm 18.02$ \\
\hline t-test $(p)^{1}$ & \multicolumn{4}{|c|}{$7.149(0.000)^{*}$} \\
\hline $\mathrm{t}$-test $(\mathrm{p})^{2}$ & \multicolumn{4}{|c|}{$10.907(0.000)^{*}$} \\
\hline $\mathrm{t}$-test $(\mathrm{p})^{3}$ & \multicolumn{4}{|c|}{$10.864(0.000)^{*}$} \\
\hline $\begin{array}{l}\text { Post stroke depression } \\
\text { (PHQ) }\end{array}$ & $20.22 \pm 7.03$ & $16.24 \pm 10.74$ & $13.62 \pm 13.02$ & $12.4 \pm 14.31$ \\
\hline $\mathrm{t}$-test $(\mathrm{p})^{1}$ & \multicolumn{4}{|c|}{$4.753(0.000)$} \\
\hline $\mathrm{t}$-test $(\mathrm{p})^{2}$ & \multicolumn{4}{|c|}{$5.524(0.000)$} \\
\hline $\mathrm{t}$-test $(\mathrm{p})^{3}$ & \multicolumn{4}{|c|}{$5.634(0.000)$} \\
\hline
\end{tabular}

Paired-sample t-test $(\mathrm{p})^{1}$ :comparing pre program and 1 month after

Paired-sample t-test $(\mathrm{p})^{2}$ :comparing pre program and 3 month after 
Paired-sample t-test $(\mathrm{p})^{3}$ :comparing pre program and 6 month after

*Significance at $\mathrm{p} \leq 0.05$

Table 7 shows that no correlation found between the total knowledge and practice score of the caregivers and the functional status and post-stroke depression of the geriatric patients' pre and post the implementation of the training program.

Table (7): Correlation between the functional status and post-stroke depression of geriatric patients and caregivers' knowledge and practices pre-post the training program implementation

\begin{tabular}{|c|c|c|c|c|c|c|c|c|}
\hline \multirow{3}{*}{ Item } & \multicolumn{4}{|c|}{ Functional status (FIM) } & \multicolumn{4}{|c|}{ Post stroke depression (PHQ) } \\
\hline & \multicolumn{2}{|c|}{ Before sessions } & \multicolumn{2}{|c|}{ After 1 month } & \multicolumn{2}{|c|}{ Before sessions } & \multicolumn{2}{|c|}{ After 1 month } \\
\hline & $\mathbf{r}$ & $\mathbf{P}$ & $\mathbf{r}$ & $\mathbf{P}$ & $\mathbf{r}$ & $\mathbf{P}$ & $\mathbf{r}$ & $\mathbf{P}$ \\
\hline Total knowledge score & 0.006 & 0.967 & 0.045 & 0.770 & 0.170 & 0.263 & 0.018 & 0.908 \\
\hline Total practice score & 0.238 & 0.116 & 0.051 & 0.737 & 0.021 & 0.890 & 0.114 & 0.454 \\
\hline
\end{tabular}

*. Correlation is significant at the 0.05 level (2-tailed).

**. Correlation is significant at the 0.01 level (2-tailed).

Table 8 revealed that there is a statistically significant negative correlation found between the functional status and post-stroke depression of the studied subjects pre and post the implementation of the training program. As the improvement in functional status was carried with improvement in the emotional status of the geriatric patients (post-stroke depression was decreased).

Table (8): Correlation between the functional status and post-stroke depression of the studied subjects' pre-post the training program implementation

\begin{tabular}{|c|c|c|c|c|c|c|c|c|}
\hline \multirow{3}{*}{$\begin{array}{l}\text { Post Stroke Depression } \\
\text { (PHQ) }\end{array}$} & \multicolumn{8}{|c|}{ Functional Status (FIM) } \\
\hline & \multicolumn{2}{|c|}{ Before sessions } & \multicolumn{2}{|c|}{ After 1 month } & \multicolumn{2}{|c|}{ After 3 months } & \multicolumn{2}{|c|}{ After 6 months } \\
\hline & $\mathbf{r}$ & $\mathbf{P}$ & $\mathbf{r}$ & $\mathbf{P}$ & $\mathbf{r}$ & $\mathbf{P}$ & $\mathbf{r}$ & $\mathbf{P}$ \\
\hline Before sessions & $0.485 * *$ & 0.001 & & & & & & \\
\hline After 1 month & & & $0.564 * *$ & 0.000 & & & & \\
\hline After 3 months & & & & & $0.657 * *$ & 0.000 & & \\
\hline After 6 months & & & & & & & $0.655 * *$ & 0.000 \\
\hline
\end{tabular}

*. Correlation is significant at the 0.05 level (2-tailed).

**. Correlation is significant at the 0.01 level (2-tailed).

\section{Discussion}

Stroke is a global health problem and a serious medical emergency that requires immediate medical attention. It is associated with greater disability and mortality with increasing age and often considered a disease of the older adults because approximately $60 \%$ to $75 \%$ of all strokes occur in persons over 65 years of age ${ }^{28,29}$. This is because of older adults' diminished physiologic, functional, and social reserves in combination with common secondary complications of stroke such as functional/cognitive impairment, falls, pneumonia, dysphagia, malnutrition, urinary incontinence, and depression. Together these may ultimately lead to higher rates of recurrent hospitalization, longer lengths of hospital stay, poorer quality of life, increased costs, excessive caregiver strain, and premature institutionalization and/or death of the elderly ${ }^{30,31}$. Previous researches reported that $85 \%-95 \%$ of family caregivers are untrained and often lack sufficient caregiving knowledge and skills $^{13,32}$. Also, it was apparent that, supplementing information and emotional support to informal caregivers with specific training in basic nursing skills and activities of daily living improves the outcome of disabled stroke survivors. Therefore, this study aimed to determine the impact of informal caregivers training program on geriatric patients' functional status and post-stroke depression.

On examining the effect of the implemented program, the present study revealed that, before application of the training program all caregiver's knowledge and practice level was poor, while immediately after the implementation of the training program, the level of knowledge and practices improved to a great extent. A highly statistically significant difference was found between total knowledge and practices score pre and post the implementation of the program. This is in accordance with a study carried out by Hamad $(2001)^{33}$ $\&$ Farahat et al $(2008)^{17}$. Also, congruent with the present study finding, all the family caregivers of the poststroke patients in a study carried out by Abd El Ghany $(2006)^{34}$, recorded a significant improvement in knowledge and practices after health education sessions whether in post-test one or two compared to their initial assessment done through the pre-test. The results of the present study may be interpreted as increased 
knowledge and practices level of the caregivers are related to the effectiveness of the training program sessions which gives the caregivers the information needed for care of geriatric patients with stroke and also helped them to be competent in providing care for patients with stroke and consequently save effort and time needed for nursing care as well as increase of self confidence of the caregivers. From that we should highlighted the importance of education and training of family caregivers of stroke patients regarding to knowledge that allow primary, secondary and tertiary preventive measures.

Evaluation of functional status of elderly after the implementation of the training program illustrate that, there was an increase in functional status of the elderly patients over the 6 month follow-up period. Also, a statistically significant difference was found between functional status pre and post the application of the training program. A similar finding to the present study also was presented in a study done by Abd Elhameed $(2010)^{27} \&$ Hadidi $(2008)^{35}$. While, Eftekhar $(2008)^{36}$ report that the majority of Iranian post stroke clients surveyed required assistance with activities of daily living (ADLs). The improvement in patients' level of independence in the current study may be due to effectiveness of treatment, effective care provided post discharge and the planned follow-up as well as the effectiveness of the caregiver training program implemented by the researchers. From reviewing different literature, the majority of functional recovery occurs during the first three months following stroke. So, it is important to emphasize in providing the necessary information related to the care of stroke patients from health care providers during the hospitalization and early discharge stage.

Positive emotions have recently been shown to be both protective of stroke and may be an important modifiable factor in recovery of functional status post stroke $\mathrm{e}^{24}$. The Post-stroke depression (PSD) is a common consequence of stroke with an estimated prevalence ranging from twenty fifes to seventy nine percent. A clear understanding of the phenomenon of post-stroke depression and functional outcome will provide insight and assist clinicians in early identification of high risk patients who most likely will benefit from treatment interventions. This in turn, may lead to an improved quality of life, shorter hospital stay, reduced health care cost and reduced mortality ${ }^{36}$. A significant change in the level of depression among elderly was observed over the six month follow-up period in this study. The results of the present study revealed also that, there is an improvement in level of post-stroke depression and the difference before and after the training program implementation was statistically significant. This result was in accordance with the result of Kalra et al. $(2004)^{21}$. Also a statistically significant positive correlation between functional status of the elderly and Poststroke depression was found. This result is in line with the results of Seale $(2010)^{24}$, who found that the study sample experienced gains in positive emotion over the 12-month follow-up. This means, the high level of independency (functional status) of the elderly was associated with improvement in emotional status as manifested by the decrease in the level of depression. These results may be related to the adherence of the caregivers with the knowledge and practices learned from the training program and from the instructions and advices given by the researchers to them during the follow up visits. As well as, it may be related to the adherence of patients to their medical treatment. So it is important to focus in functional rehabilitation program immediately following stroke occurrence and on the educational and intervention training program to caregivers.

\section{Conclusion}

According to the results of the present study, it can be concluded that, caregivers training affect positively the geriatric patients' functional status and post-stroke depression. An improvement in the geriatric patients' functional status and post-stroke depression after implementation of the training program was observed and also the caregivers' knowledge and practices level was improved. Moreover, an improvement in functional status of geriatric patients is associated with a low score of post-stroke depression after the training program implementation and the relation between them was statistically significant.

Based on the results of this study the following recommendations are suggested:

- $\quad$ Training programs for formal and informal caregivers about stroke and its managements to be planned by nurse gerontologist and specialists in hospitals and offered on a regular basis.

- A large scale study needed to conduct by a nurse researcher to geriatric patients post stroke in the hospitals to evaluate the outcome of caregivers training program.

\section{Acknowledgement}

We would like to extend our deep thanks to all health personnel in the inpatients \& outpatients' neurological departments of El-Mansoura university hospital as well as the patients and their informal caregiver who agreed to participate in the study for their cooperation in the fulfillment of this work. 


\section{References}

[1] Buttero T, Trybulski J, Bailey P and Cook J. Primary Care: A collaborative Practice. $3^{\text {rd }}$ ed., St. Louis: Mosby Inc., 2008; $1031-36$.

[2] American Heart Association/ American Stroke Association. Guidelines for early management of patients with acute ischemic stroke. 2013. Available at: http://www.ahajournals.org . Accessed on 20/2/2012

[3] National Institute of Neurological Disorders and Stroke. Know the Stroke. 2009. Available at: http://www.ninds.nih.gov. Accessed on $13 / 8 / 2012$

[4] World Health Organization. World Health Report 2007. Cited in The Internet Stroke Center. Stroke Statistics. 2009. Available at: http://www.strokecenter.org. Accessed on 1/3/2012.

[5] Benamer H and Grosset D. Stroke in Arab countries: A systematic literature review. Journal of the Neurological Sciences, 2009, 109-81. Available at: http://www. Elsevier.com. Accessed on 13/1/2014.

[6] Sarhan E. The Problem of Stroke in Egypt. Unpublished Master Thesis. Faculty of Medicine, Cairo University. 2007.

[7] Mansoura University. Mansoura University Hospital Statistical Record.2011.

[8] Patel A, Duncan P, Lai S \& Studenski. The relation between impairments and functional outcomes post-stroke. Archives of Physical Medicine and Rehabilitation, 81, 2000;1357-63.

[9] Katrak P, Black D \& Peera V (2009). Do stroke patients with intracerebral hemorrhage have better functional outcomes than patients with cerebral infarctions? Physical Medicine and Rehabilitation, 1, 427-433.

[10] Hanjo K, Iso H, Ikeda A, Inoue M \& Tsugane S (2009). Education level and physical function limitations among Japanese community residents - gender differences in progress from stroke. Bio Med Central Public Health, 9, 131-9.

[11] Lökk J and Delbari A (2010). Management of depression in elderly stroke patients. Dovepress Journal, 6(1): 539 - 49. Available at: http://dx.doi.org. Accessed on 5/4/ 2012.

[12] Hackett M, Yapa C, Parag V \& Anderson C (2005). Frequency of depression after stroke: a systematic review of observational studies. Stroke, 36, 1330- 40 .

[13] Wu C (2009). Learning to be a Family Caregiver for Severely Debilitated Stroke Survivors during the First year in Taiwan. Published Doctorate Dissertation. Faculty of Graduate College, Lowa University. Available at: http://proquest.umi.com. Accessed on $11 / 1 / 2012$.

[14] Forster A, Dickerson J, Young J, Patel A, Kalra L, Nixon J, Smithard D, Knapp M, Holloway I, Anwar S and Farrin A (2013). A structured training programme for caregivers of inpatients after stroke (TRACS): a cluster randomized controlled trial and costeffectiveness analysis. The Lancet, 382 (9910):2069 - 76.

[15] Hinojosa M, Rittman M (2007). Stroke Caregiver Information Needs: Comparison of Mainland \& Puerto Rican caregivers. Journal of Rehabilitation Research \& Development, 44(5):649-58.

[16] Kalra L (2005). Training Relatives in Caregiving ease Burden, Aids Stroke Survivors. Journal of American Heart Association, 21(3):42.

[17] Farahat N, Ahmed H, Abd El-Azez N (2008). Efficacy of an Educational Nursing Intervention for Family Caregivers on PostStroke Disabled Patients. The New Egyptian Journal of Medicine, 38(6):422- 42.

[18] Smith L, Lawrence M, Kerr S, Langhorne P, Lees K (2004). Informed Carers' Experience of Caring for Stroke Survivors. Journal of Advanced Nursing, 46(3):235- 44.

[19] Clarke1 D, Godfrey M, Hawkins R, Sadler E, Harding G, Forster A, Mc Kevitt C, Dickerson J and Farrin A (2013). Implementing a training intervention to support caregivers after stroke: a process evaluation examining the initiation and embedding of programme change. Implementation Science, 8:96

[20] Walling A (2005). Caregiver Training and Outcomes in Stroke Patients. Journal of the American Academy of Family Physicians, 71(5): 990. Available at: http://www.afpserv.org. Accessed on 1/3/ 2012.

[21] Kalra L, Evans A, Perez I (2004). Training Carers of Stroke Patients: Randomized Controlled Trial. British Medical Journal, 328 : 1099-1110.

[22] Hamilton B, Granger V, Sherwin S, Zielezny M and Tashman S. A uniform national data system for medical rehabilitation. In: Fuhrer M, ed. Rehabilitation outcomes: analysis and measurement. Baltimore: Brookes, 1987:137-147. Available at: http://www.tbims.org. Accessed on 11/1/2012.

[23] Center for Medicare and Medicaid Services (2003). The inpatient Rehabilitation Facility-Patient Assessment Instrument (IRF-PAI) Training Manual. UB Foundation Activities. Available at: http://www.cms.gov. Accessed on 10/1/2012.

[24] Seale G, Berges I, Ottenbacher J \& Ostir G (2010). Change in positive emotion and recovery of functional status following stroke. Rehabilitation Psychology, 55, 33-9.

[25] Spitzer R, Williams J, Kroenke K and colleagues with an educational grant from Pfizer Inc. (1999). Department of Psychiatry and Behavioral Sciences Program (IMPACT), Washington University. Pfizer Inc. Available at: http://impact-uw.org. Accessed on $10 / 1 / 2012$.

[26] Loewe B, Unutzer J, Challahan C, Perkins A, Kroenke K (2004). Monitoring depression treatment outcomes with the patient health questionnaire-9. Med Care ;42: 1194-201. Available at: http://uwaims.org. Accessed on 5/1/ 2012.

[27] Abd Elhameed S (2010). Caregivers Training and Health Status Outcomes in Cerebral Stroke Elder Patients. Unpublished Doctorate Dissertation. Faculty of Nursing, Alexandria University.

[28] Feigin V (2005). Stroke Epidemiology in the Developing World. Lancet, 365(9478): 2160-1.

[29] Ibrahim N (2007). Assessment of Biopsychosocial Needs for Patients with Chronic Cerebrovascular Stroke. Unpublished Master Thesis. Faculty of Nursing, Ain Shams University.

[30] Daffershofer M, Mielko O, Pullwitt A, et al. (2004). Transient Ischemic Attacks are More Than "Ministrokes". Stroke, 35: 245385.

[31] Mohamed M (2003). Effect of a Rehabilitation Nursing Program on the Function Outcome of Acute Ischemic Stroke Adult Patients. Unpublished Doctorate Dissertation. Faculty of Nursing, Cairo University.

[32] Sun J, Huang M, Sung M, Chen S, Lee S, \& Wang H (2005). Quality of Life and Social Support of Primary Caregivers for Patients with Cerebral Vascular Accident. Formosan Journal of Medicine, 9(3): 303-11.

[33] Hamad A (2001). Stroke in Qatar: A one year, Hospital Based Study. Journal of Stroke and Cerebrovascular Disease, 10: $236-41$.

[34] Abd El Ghany F (2006). Post-Stroke Home Health Care; Impact on Patients' Condition and Family Caregivers' Burden. Unpublished Doctorate Dissertation. Faculty of Nursing, Cairo University.

[35] Hadidi N (2008). Post Stroke Depression and Functional Outcomes: A Pattern of Change. Published Doctorate Dissertation. Faculty of Graduated School, Minnesota University. Available at: http://proquest.umi.com. Accessed on 1/11/2011.

[36] Eftekhar P (2008). Rehabilitation Services for Post Stroke Clients in Tehran, Iran. Thesis, Msc, Toronto: Graduated department of rehabilitation science, University of Toronto. Available at: http://proquest.umi.com. Accessed on 1/11/2011. 